\title{
Intelligence and Substance Use
}

\author{
Satoshi Kanazawa \\ London School of Economics and Political Science \\ Josephine E. E. U. Hellberg \\ University College London
}

\begin{abstract}
Why do some individuals choose to drink alcohol, smoke cigarettes, and use illegal drugs while others do not? The origin of individual preferences and values is one of the remaining theoretical questions in social and behavioral sciences. The Savanna-IQ Interaction Hypothesis suggests that more intelligent individuals may be more likely to acquire and espouse evolutionarily novel values than less intelligent individuals. Consumption of alcohol, tobacco, and drugs is evolutionarily novel, so the Savanna-IQ Interaction Hypothesis would predict that more intelligent individuals are more likely to consume these substances. Analyses of two large, nationally representative, and prospectively longitudinal data from the United Kingdom and the United States partly support the prediction. More intelligent children, both in the United Kingdom and the United States, are more likely to grow up to consume more alcohol. More intelligent American children are more likely to grow up to consume more tobacco, while more intelligent British children are more likely to grow up to consume more illegal drugs.
\end{abstract}

Keywords: evolutionary psychology, Savanna-IQ Interaction Hypothesis, alcohol, tobacco, drugs

Where do individuals' values and preferences come from? Why do people like or want what they do? For example, why do some individuals choose to drink alcohol, smoke cigarettes, and use illegal drugs, while others don't? The origin of individual values and preferences is one of the remaining theoretical puzzles in social and behavioral sciences (Kanazawa, 2001).

Recent theoretical developments in evolutionary psychology may suggest one possible explanation (Kanazawa, 2010b). On the one hand, evolutionary psychology (Crawford, 1993; Symons, 1990; Tooby \& Cosmides, 1990) posits that the human brain, just like any other organ of any other species, is designed for and adapted to the conditions of the ancestral environment (roughly the African savanna during the Pleistocene Epoch), not necessarily to those of the current environment. It may therefore have difficulty comprehending and dealing with entities and situations that did not exist in the ancestral environment (Kanazawa, 2002, 2004a). On

Satoshi Kanazawa, Department of Management, London School of Economics and Political Science; and Josephine E. E. U. Hellberg, Department of Genetics, Evolution and Environment, University College London.

This research uses data from Add Health, a program project designed by J. Richard Udry, Peter S. Bearman, and Kathleen Mullan Harris, and funded by a grant P01-HD31921 from the Eunice Kennedy Shriver National Institute of Child Health and Human Development, with cooperative funding from 17 other agencies. Special acknowledgment is due Ronald R. Rindfuss and Barbara Entwisle for assistance in the original design. Persons interested in obtaining data files from Add Health should contact Add Health, Carolina Population Center, 123 West Franklin Street, Chapel Hill, NC 27516-2524, (addhealth@unc.edu). No direct support was received from grant P01-HD31921 for this analysis. We thank Ian J. Deary, Christine Horne, Evelyn Korn, Diane J. Reyniers, and anonymous reviewers for their comments on earlier drafts.

Correspondence concerning this article should be addressed to Satoshi Kanazawa, Managerial Economics and Strategy Group, Department of Management, London School of Economics and Political Science, Houghton Street, London WC2A 2AE, United Kingdom. E-mail: S.Kanazawa@ lse.ac.uk the other hand, an evolutionary psychological theory of the evolution of general intelligence proposes that general intelligence may have evolved as a domain-specific adaptation to solve evolutionarily novel problems, for which there are no predesigned psychological adaptations (Kanazawa, 2004b, 2008, 2010b).

The logical conjunction of these two theories, the Savanna-IQ Interaction Hypothesis (the Hypothesis; Kanazawa, 2010a), implies that the human brain's difficulty with evolutionarily novel stimuli may interact with general intelligence, such that more intelligent individuals have less difficulty with such stimuli than less intelligent individuals. In contrast, general intelligence may not affect individuals' ability to comprehend and deal with evolutionarily familiar entities and situations. ${ }^{1}$

Evolutionarily novel entities that more intelligent individuals are better able to comprehend and deal with may include ideas and lifestyles, which form the basis of their values and preferences; it would be difficult for individuals to prefer or value something that they cannot truly comprehend. Hence, applied to the domain of preferences and values, the Hypothesis suggests that more intelligent individuals are more likely to acquire and espouse evolutionarily novel preferences and values that did not exist in the ancestral environment than less intelligent individuals, but general intelli-

\footnotetext{
${ }^{1}$ Evolutionarily novel entities and situations are those that did not exist in the ancestral environment, roughly before the end of the Pleistocene Epoch 10,000 years ago, and evolutionarily familiar entities and situations are those that existed in the ancestral environment more than 10,000 years ago. Virtually all of the physical objects we find in our daily lives today-computers, automobiles, television, buildings, houses, cities, and agriculture-are evolutionarily novel, except for categories of other humans (men, women, boys, and girls). In contrast, many of the social relationships-pair-bonds, friendships, strategic coalitions, parent-child relationships-are evolutionarily familiar, even though they may also involve evolutionarily novel elements in them-church weddings, Facebook friends, legally enforceable contracts, and paid daycare centers. We are mute on whether the concept of evolutionary novelty is binary, where something is either evolutionarily novel or evolutionarily familiar, or quantitative, with degrees of evolutionary novelty.
} 
gence has no effect on the acquisition and espousal of evolutionarily familiar preferences and values that existed in the ancestral environment (Kanazawa, 2010a).

There has been emerging evidence for the Hypothesis as an explanation for individual preferences and values. First, more intelligent children are more likely to grow up to espouse left-wing liberalism (Deary, Batty, \& Gale, 2008; Kanazawa, 2010a), possibly because genuine concerns with genetically unrelated others and willingness to contribute private resources for the welfare of such others-liberalism-may be evolutionarily novel. Even though past studies show that women are more liberal than men (Lake \& Breglio, 1992; Shapiro \& Mahajan, 1986; Wirls, 1986), and Blacks are more liberal than Whites (Kluegel \& Smith, 1989; Sundquist, 1983), the effect of childhood intelligence on adult liberalism is twice as large as the effect of sex or race (Kanazawa, 2010a).

Second, more intelligent children are more likely to grow up to be atheists (Kanazawa, 2010a), possibly because belief in higher powers, as a consequence of overinference of agency behind otherwise natural phenomena, may be part of evolved human nature (Atran, 2002; Boyer, 2001; Guthrie, 1993; Haselton \& Nettle, 2006; Kirkpatrick, 2005), and atheism may therefore be evolutionarily novel. Even though past studies show that women are much more religious than men (Miller \& Hoffmann, 1995; Miller \& Stark, 2002), the effect of childhood intelligence on adult religiosity is twice as large as that of sex (Kanazawa, 2010a).

Third, more intelligent boys (but not more intelligent girls) are more likely to grow up to value sexual exclusivity (Kanazawa, 2010a), possibly because humans were naturally polygynous throughout evolutionary history (Alexander, Hoogland, Howard, Noonan, \& Sherman, 1977; Harvey \& Bennett, 1985; Kanazawa \& Novak, 2005; Leutenegger \& Kelly, 1977; Pickford, 1986). Either under monogamy or polygyny, women are expected to be sexually exclusive to one mate; in sharp contrast, men in polygynous marriage are not expected to be sexually exclusive to one mate, whereas men in monogamous marriage are. So sexual exclusivity may be evolutionarily novel for men, but not for women.

Fourth, more intelligent children are more likely to grow up to be nocturnal, going to bed and waking up later (Kanazawa \& Perina, 2009), possibly because nocturnal life was rare in the ancestral environment where our ancestors did not have artificial sources of illumination until the domestication of fire. Ethnographies of contemporary hunter-gatherers suggest that our ancestors may have woken up shortly before dawn and gone to sleep shortly after dusk. Night life may therefore be evolutionarily novel.

Finally, criminals on average have lower intelligence than the general population (Wilson \& Herrnstein, 1985; Herrnstein \& Murray, 1994). This is consistent with the Hypothesis because, while much of what we call interpersonal crime today is evolutionarily familiar, the institutions that control, detect, and punish such behavior are evolutionarily novel (Kanazawa, 2009). Murder, assault, robbery and theft were probably routine means of intrasexual male competition for resources and mates in the ancestral environment. We may infer this from the fact that behavior that would be classified as criminal if engaged in by humans are quite common among other species (Ellis, 1998), including other primates (de Waal, 1989, 1992; de Waal, Luttrell, \& Canfield, 1993). However, there was very little formal third-party enforcement of norms in the ancestral environment, only second-party enforcement (victims and their kin and allies) or informal third-party enforcement (ostracism). It therefore makes sense from the perspective of the Hypothesis that men with low intelligence may be more likely to resort to evolutionarily familiar means of competition for resources (theft rather than full-time employment) and mating opportunities (rape rather than computer dating) and not to comprehend fully the consequences of criminal behavior imposed by evolutionarily novel entities of law enforcement.

\section{Evolutionary Novelty of Alcohol, Tobacco, and Drugs}

\section{Alcohol}

The human consumption of alcohol probably originates from frugivory (consumption of fruits; Dudley, 2000). Fermentation of sugars by yeast naturally present in overripe and decaying fruits produces ethanol, known to intoxicate birds and mammals (Vallee, 1998). However, the amount of ethanol alcohol present in such fruits ranges from trace to $5 \%$, roughly comparable to light beer $(0-4 \%)$. It is nothing compared to the amount of alcohol present in regular beer (4-6\%), wine (12-15\%), and distilled spirits (20-95\%).

"Ingestion of alcohol, however, was unintentional or haphazard for humans until some 10,000 years ago" (Vallee, 1998, p. 81), and "intentional fermentation of fruits and grain to yield ethanol arose only recently within human history" (Dudley, 2000, p. 9). The production of beer, which relies on a large amount of grain, and wine, which similarly requires a large amount of grapes, could not have taken place before the advent of agriculture around 8,000 BC. Archeological evidence dates the production of beer and wine to Mesopotamia at about 6,000 BC (Dudley, 2000). The origin of distilled spirits is far more recent, and is traced either to Middle East or China at about $700 \mathrm{AD}$. The word alcohol—al kohl—is Arabic in origin.

"Relative to the geological duration of the hominid lineage, therefore, exposure of humans to concentrations of ethanol higher than those attained by fermentation alone [that is, at most 5\%] is strikingly recent" (Dudley, 2000, p. 9). Further, any "unintentional or haphazard" consumption of alcohol in the ancestral environment, via the consumption of overripe and decaying fruits, happened as a result of eating, not drinking, whereas alcohol is almost entirely consumed today via drinking. The Savanna-IQ Interaction Hypothesis would therefore predict that more intelligent individuals may be more likely to prefer drinking modern alcoholic beverages (beer, wine, and distilled spirits) than less intelligent individuals, because the substance and the method of consumption are both evolutionarily novel.

Consistent with the Hypothesis, an analysis of a large representative sample from the prospectively longitudinal 1970 British Cohort Study shows that childhood IQ at age 10 increases both the quantity and frequency of drinking, as well as problem drinking, at age 30 (Batty et al., 2008). Similarly, a behavior genetic analysis of twin pairs from the Minnesota Twin Family Study shows that, controlling for genetic and shared environmental influences, men and women with higher IQ at age 17 are more likely to use alcohol at age 24 (Johnson, Hicks, McGue, \& Iacono, 2009).

On the other hand, in a prospectively longitudinal study of 456 boys from Boston, childhood IQ does not distinguish abstainers from all categories of drinkers in adulthood (moderate drinkers, heavy drinkers, alcohol abusers; Vaillant, 1995, p. 135, Table 3.4, p. 216, 
Table 3.15). However, the sample is small and unrepresentative, especially with respect to childhood IQ; only a third (33\%) of the sample have childhood IQ above 100 (Vaillant, 1995, p. 326).

\section{Tobacco}

The human consumption of tobacco is more recent in origin than that of alcohol. The tobacco plant originated in South America and spread to the rest of the world (Goodspeed, 1954). Native Americans began cultivating two species of the tobacco plant (Nicotiana rustica and Nicotiana tabacum) about 8,000 years ago (Wilbert, 1991). The consumption of tobacco was unknown outside of the Americas until Columbus brought it back to Europe at the end of the 15th Century (Goodman, 1993; Smith, 1999). The consumption of tobacco is therefore evolutionarily novel, and the Savanna-IQ Interaction Hypothesis would predict that more intelligent individuals may be more likely to consume tobacco than less intelligent individuals.

Consistent with the Hypothesis, Johnson et al. (2009) find that young men and women with higher IQ at age 17 are more likely to use nicotine at age 24. On the other hand, Batty, Deary, Schoon, Emslie, et al.'s (2007) analysis of the 1970 British Cohort Study shows that those with higher IQ at age 5 or 10 have smaller odds of being a smoker at age 30. Similarly, Batty, Deary, and Macintyre's (2007) study of the Aberdeen Children of the 1950s study shows that higher childhood intelligence is associated with lower odds of smoking 40 years later.

\section{Drugs}

Most psychoactive drugs have even more recent historical origin than alcohol and tobacco; "before the rise of agriculture, access to psychoactive substances likely was limited" (Smith, 1999, p. 377). The use of opium dates back to about 5,000 years ago (Brownstein, 1993), and the earliest reference to the pharmacological use of cannabis is in a book written in 2737 BC by the Chinese Emperor Shen Nung (Smith, 1999, pp. 381-382). Other psychoactive drugs require modern chemical procedures to manufacture, and are therefore of much more recent origin: Morphine was isolated from opium in 1806 (Smith, 1999); heroin was discovered in 1874 (Smith, 1999); and cocaine was first manufactured in 1860 (Holmstedt \& Fredga, 1981).

There have been several studies on the effect of drug use on intelligence, both the effect of individual use on the same individual's cognitive performance later and the parent's prenatal use on the children's intelligence. However, to the best of our knowledge, there have been no studies that examine the effect of individual intelligence on the use of psychoactive substances, to see whether more intelligent individuals are more or less likely to use such substances.

Given that the consumption of alcohol, tobacco, and psychoactive drugs is all evolutionarily novel- unknown before the end of the Pleistocene 10,000 years ago-the Savanna-IQ Interaction Hypothesis would predict that more intelligent individuals are more likely to consume all such substances than less intelligent individuals. Because both Openness to Experience (Ackerman \& Heggestad, 1997) and sensation seeking (Raine, Reynolds, Venables, \& Mednick, 2002) are positively associated with general intelligence, these personality traits can serve as proximate causes of substance consumption. We will test this prediction with two large, nationally representative, and prospectively longitudinal data from the United Kingdom and the United States.

\section{Study 1}

\section{Data}

The National Child Development Study (NCDS) is a large-scale prospectively longitudinal study which has followed a population of British respondents since birth for more than half a century. The study includes all babies $(n=17,419)$ born in Great Britain (England, Wales, and Scotland) during one week (March 03-09, 1958). The respondents are subsequently re-interviewed in 1965 (Sweep 1 at age 7;n=15,496), in 1969 (Sweep 2 at age 11; $n=18,285^{2}$ ), in 1974 (Sweep 3 at age 16; $n=14,469$ ), in 1981 (Sweep 4 at age 23; $n=12,537$ ), in 1991 (Sweep 5 at age 33; $n=11,469$ ), in 1999-2000 (Sweep 6 at age 41-42; $n=11,419$ ), and in 2004-2005 (Sweep 7 at age 46-47; $n=9,534$ ). In each Sweep, personal interviews and questionnaires are administered to the respondents, to their mothers, teachers, and doctors during childhood, and to their partners and children in adulthood.

Nearly all $(97.8 \%)$ of the NCDS respondents are Caucasian. There are so few respondents in other racial categories that, if we control for race with a series of dummies in multiple regression analyses, it often results in too few cell cases to arrive at stable estimates for coefficients. We therefore do not control for respondents' race in our analysis of the NCDS data. The full descriptive statistics for all the variables included in the regression analysis below (means, standard deviations, and full correlation matrix) are presented in the Appendix (Table A1).

\section{Dependent Variables}

Alcohol: Frequency. At ages 23, 33, and 42, NCDS asks its respondents about the frequency of their alcohol consumption with the question "How often do you usually have an alcoholic drink of any kind? $0=$ never, $1=$ only on special occasions, $2=$ less often than once a week, $3=$ once or twice a week, $4=$ most days. We perform a factor analysis with the three measures of the frequency of alcohol consumption at three different ages to construct a latent measure of the frequency of alcohol consumption over the life course. The three indicators load very heavily on one latent factor with high factor loadings (age $23=.766$, age $33=.862$, age $42=$ .839). We use the latent factor as a measure of the frequency of alcohol consumption.

Alcohol: Quantity. In addition, at ages 23, 33, and 42, NCDS asks its respondents about the quantity of their consumption of different alcoholic beverages with the question "In the last seven days, how much [type of beverage] have you had?" At ages 23 and 33, NCDS asks about beer, spirits, wine, and martini; at age 42, it asks about beer, spirits, wine, sherry, and alcopops (flavored alcoholic drinks like wine cooler). For each type of alcoholic beverage, the respondents can indicate the quantity in terms of pints (for beer), measures (for spirits), glasses (for wine and martini), or bottles (for alcopops). For each age, we perform a separate factor analysis with all types of alcoholic beverages. At every age, all beverage types load on a single latent factor with reasonably high factor loadings

\footnotetext{
${ }^{2}$ There are more respondents in Sweep 2 than in the original sample (Sweep 0) because the Sweep 2 sample includes eligible children who were in the country in 1969 but not in 1958 when Sweep 0 interviews were conducted.
} 
(age 23: beer $=.392$, spirits $=.749$, wine $=.712$, martini $=.405$; age 33: beer $=.421$, spirits $=.717$, wine $=.638$, martini $=.367$; age 42: beer $=.523$, spirits $=.651$, wine $=.396$, sherry $=.199$, alcopops $=.498)$. We then perform a second-order factor analysis to construct a latent measure of the quantity of alcohol consumption over the life course. The three latent measures for each age load on a single factor with high factor loadings (age $23=.671$, age $33=.779$, age $42=.714$ ). We use the second-order factor as a measure of the quantity of alcohol consumption.

Tobacco. At ages 23, 33, 42, and 47, NCDS asks its respondents how many cigarettes a day they usually smoke. We perform a factor analysis with their responses at four different ages to construct a latent measure of cigarette consumption over the life course. The four indicators load on a single latent factor with very high factor loadings (age $23=.813$, age $33=.896$, age $42=.903$, age $47=.879)$. We use the latent factor as a measure of tobacco consumption.

Drugs. At age 42 only, NCDS asks its respondents whether they have ever tried 13 different types of illegal psychoactive drugs (cannabis, ecstasy, amphetamines, LSD, amyl nitrate, magic mushrooms, cocaine, temazepan, semeron, ketamine, crack, heroine, methadone). Their response can be: $0=$ never, $1=$ yes, but not in the last 12 months, 2 = yes, in the last 12 months. We perform a factor analysis with their responses for the 13 different types of illegal drugs. They load on a single factor with reasonably high factor loadings (cannabis $=.540$, ecstasy $=.653$, amphetamines $=.714$, LSD $=.691$, amyl nitrate $=.610$, magic mushrooms $=.637$, cocaine $=.746$, temazepan $=.370$, semeron $=.303$, ketamine $=.479$, crack $=.582$, heroine $=.694$, methadone $=.566$ ). We use the latent factor as a measure of drug consumption.

\section{Independent Variable: Childhood General Intelligence}

The NCDS respondents take multiple intelligence tests at ages 7, 11, and 16. At age 7, the respondents take four cognitive tests (Copying Designs Test, Draw-a-Man Test, Southgate Group Reading Test, and Problem Arithmetic Test). At age 11, they take five cognitive tests (Verbal General Ability Test, Nonverbal General Ability Test, Reading Comprehension Test, Mathematical Test, and Copying Designs Test). At age 16, they take two cognitive tests (Reading Comprehension Test, and Mathematics Comprehension Test). We first perform a factor analysis at each age to compute their general intelligence score for each age. All cognitive test scores at each age load only on one latent factor, with reasonably high factor loadings (Age 7: Copying Designs Test $=.671$, Draw-a-Man Test $=.696$, Southgate Group Reading Test $=.780$, and Problem Arithmetic Test $=.762$; Age 11: Verbal General Ability Test $=.920$, Nonverbal General Ability Test $=.885$, Reading Comprehension Test $=.864$, Mathematical Test $=.903$, and Copying Designs Test $=.486$; Age 16: Reading Comprehension Test $=.909$, and Mathematics Comprehension Test $=.909$ ). The latent general intelligence factors at each age are converted into the standard IQ metric, with a mean of 100 and a standard deviation of 15 . Then we perform a second-order factor analysis with the IQ scores at three different ages to compute the overall childhood general intelligence score. The three IQ scores load only on one latent factor with very high factor loadings (Age $7=.867$; Age $11=.947$; Age $16=.919)$. We use the childhood general intelligence score in the standard IQ metric as our main independent variable.

\section{Control Variables}

In addition to childhood general intelligence, we control for the following variables in our ordinary least squares regression equations: sex $(0=$ female, $1=$ male); religion (with four dummies for Catholic, Anglican, other Christians, and other religions, with none as the reference category); frequency of church attendance $(0=$ no religion, $1=$ rarely or never, $2=$ less than monthly, $3=$ monthly or more, $4=$ weekly or more); whether currently married ( $1=$ yes); whether ever married $(1=$ yes); number of children; education (years of formal schooling); earnings (in $£)$; whether diagnosed as depressed $(1=$ yes); general satisfaction with life (on a 10-point scale); social class at birth measured by father's occupation ( $1=$ unskilled, $2=$ semiskilled, $3=$ skilled, $4=$ white-collar, $5=$ professional); mother's education (years of formal schooling); father's education (years of formal schooling).

Our primary focus is the use of psychoactive substances which are highly addictive. Once individuals start using these substances, it is likely that they become accustomed or even addicted and continue to use them later in their lives. We therefore choose to measure the control variables early in their lives to see if their circumstances in early adulthood may affect their substance use for their entire life course. All of the control variables are measured at age 23 , with the following exceptions.

Due to highly complex systems of examinations, qualifications, and certifications in the United Kingdom, education in NCDS is never measured quantitatively, as years of formal schooling, except at age 42; however, $96.5 \%$ of NCDS respondents have completed their formal schooling before age 23. General satisfaction with life is only measured at age 33. Social class at birth is measured at age 0 . Mother's and father's education are measured at age 16.

\section{Results}

Table 1, first column, shows that, net of sex, religion, frequency of church attendance, marital status, number of children, education, earnings, depression, general satisfaction with life, social class at birth, mother's education, and father's education, more intelligent individuals consume alcohol more frequently throughout their lives than less intelligent individuals. The more intelligent NCDS respondents are as children, the more frequently they consume alcohol as adults. This is consistent with the prediction of the Hypothesis. A comparison of standardized regression coefficients reveals that childhood general intelligence has a stronger effect on the frequency of alcohol consumption than any other variable included in the equation, except for sex.

Men consume alcohol significantly more frequently than do women, as do Roman Catholics and Anglicans relative to atheists and agnostics. However, frequency of church attendance has a negative association with alcohol consumption, as does number of children at age 23. Earnings and father's education have positive associations with the frequency of alcohol consumption.

Table 1, second column, shows that, net of the same control variables, more intelligent individuals consume larger quantities of alcohol than less intelligent individuals. The more intelligent NCDS respondents are before 16, the greater quantities of alcohol they consume after age 23. Once again, childhood general intelligence has a greater effect on the quantity of adult alcohol consumption than any other variable in the equation, except for sex. The effects of control 
Table 1

Associations Between General Intelligence and Substance Use National Child Development Study (United Kingdom)

\begin{tabular}{|c|c|c|c|c|}
\hline & & & & \\
\hline & Frequency & Quantity & Tobacco & Drugs \\
\hline Childhood general intelligence & $.010^{* * * *}$ & $.008^{* * * *}$ & $-.008^{* * *}$ & $.006^{* * * *}$ \\
\hline & $(.001)$ & $(.002)$ & $(.002)$ & $(.001)$ \\
\hline & .143 & .100 & -.099 & .082 \\
\hline Sex & $.487^{* * * * *}$ & $.282^{* * * * *}$ & .051 & $.241^{* * * * *}$ \\
\hline & $(.040)$ & $(.045)$ & (.047) & $(.040)$ \\
\hline & .249 & .136 & .025 & .130 \\
\hline Religion & & & & \\
\hline Catholic & $.255^{* * *}$ & .098 & $.237^{*}$ & .071 \\
\hline & $(.082)$ & $(.092)$ & (.098) & $(.083)$ \\
\hline & .076 & .028 & .068 & .022 \\
\hline Anglican & $.116^{*}$ & .038 & .058 & -.038 \\
\hline & $(.052)$ & $(.058)$ & $(.061)$ & $(.052)$ \\
\hline & .057 & .018 & .028 & -.020 \\
\hline Other Christian & -.077 & -.060 & $.170^{*}$ & .036 \\
\hline & $(.071)$ & $(.080)$ & $(.084)$ & $(.072)$ \\
\hline & -.027 & -.020 & .059 & .014 \\
\hline Other religion & -.422 & -.670 & -.159 & -.299 \\
\hline & $(.402)$ & $(.452)$ & $(.489)$ & $(.405)$ \\
\hline & -.019 & -.029 & -.007 & -.014 \\
\hline Frequency of church attendance & $-.092^{* * *}$ & $-.063^{*}$ & $-.120^{* * * *}$ & $-.066^{* * *}$ \\
\hline & $(.023)$ & $(.026)$ & $(.027)$ & $(.024)$ \\
\hline & -.107 & -.069 & -.137 & -.081 \\
\hline Currently married & -.155 & -.162 & -.173 & $-.396^{* * * *}$ \\
\hline & $(.119)$ & $(.136)$ & $(.143)$ & $(.120)$ \\
\hline & -.080 & -.078 & -.086 & -.215 \\
\hline Ever married & .020 & .022 & .067 & .209 \\
\hline & $(.121)$ & $(.138)$ & $(.144)$ & $(.121)$ \\
\hline & .010 & .011 & .033 & .114 \\
\hline Number of children & $-.109^{* * * *}$ & -.048 & $.234^{* * * *}$ & .020 \\
\hline & $(.032)$ & $(.036)$ & $(.039)$ & $(.032)$ \\
\hline & -.073 & -.030 & .148 & .014 \\
\hline Education & .006 & -.005 & $-.012^{*}$ & .007 \\
\hline & $(.005)$ & $(.006)$ & $(.006)$ & $(.005)$ \\
\hline & .022 & -.018 & -.045 & .027 \\
\hline Earnings & $4.344^{-5 * * *}$ & $2.826^{-5 *}$ & $1.602^{-6}$ & $-1.924^{-5}$ \\
\hline & $(.000)$ & $(.000)$ & $(.000)$ & $(.000)$ \\
\hline & .092 & .057 & .003 & -.043 \\
\hline Depression & .012 & .116 & $.585^{* * * *}$ & .032 \\
\hline & $(.131)$ & $(.149)$ & (.169) & $(.132)$ \\
\hline & .002 & .015 & .072 & .005 \\
\hline Satisfaction with life & .006 & -.016 & $-.068^{* * * *}$ & $-.057^{* * * *}$ \\
\hline & $(.010)$ & $(.012)$ & $(.013)$ & $(.011)$ \\
\hline & .010 & -.027 & -.112 & -.104 \\
\hline Social class at birth & .015 & .018 & $-.055^{*}$ & -.037 \\
\hline & $(.021)$ & $(.023)$ & $(.025)$ & $(.021)$ \\
\hline & .014 & .016 & -.051 & -.038 \\
\hline Mother's education & .022 & .023 & .007 & .020 \\
\hline & $(.016)$ & (.019) & $(.019)$ & $(.017)$ \\
\hline & .028 & .028 & .008 & .027 \\
\hline Father's education & $.032^{*}$ & $.043^{* *}$ & .020 & .006 \\
\hline & $(.014)$ & $(.016)$ & $(.017)$ & $(.014)$ \\
\hline & .048 & .062 & .029 & .010 \\
\hline Constant & -1.630 & -.923 & 1.550 & -.185 \\
\hline & $(.172)$ & (.194) & $(.205)$ & $(.173)$ \\
\hline$R^{2}$ & .183 & .076 & .086 & .066 \\
\hline Number of cases & 2,587 & 2,569 & 2,189 & 2,575 \\
\hline
\end{tabular}

Note. Main entries are unstandardized regression coefficients. Numbers in parentheses are standard errors. Numbers in italics are standardized coefficients.

${ }^{*} p<.05$. ${ }^{* *} p<.01 .{ }^{* * * *} p<.001$. 
variables on the quantity of alcohol consumption are the same as their effects on the frequency of alcohol consumption, except that the negative effect of the number of children on the quantity of alcohol consumption is not statistically significant.

Table 1, third column, shows that, contrary to the prediction of the Hypothesis, net of the same control variables, more intelligent individuals consume significantly less tobacco than less intelligent individuals. The more intelligent NCDS respondents are as children, the fewer cigarettes they smoke as adults. Catholics and other Christians smoke more, as do parents with more children. Frequency of church attendance and education both have negative association with tobacco consumption. While depression and general satisfaction with life are not associated with alcohol consumption, they are with tobacco consumption; individuals who are depressed and less satisfied with life smoke more, although the direction of causality here is not clear. Smokers may become more depressed or less satisfied with life.

Table 1, fourth column, shows that, consistent with the prediction of the Hypothesis, net of the same control variables, more intelligent individuals are more likely to consume illegal psychoactive substances than less intelligent individuals. The more intelligent NCDS respondents are before 16, the more psychoactive substances they have consumed before 42 . Men are more likely to consume illegal drugs than women. Those who attend church frequently, who are currently married, and who are more satisfied with life, are less likely to use illegal drugs.

\section{Study 2}

\section{Data}

The National Longitudinal Study of Adolescent Health (Add Health) is a large, nationally representative and prospectively longitudinal study of young Americans. A sample of 80 high schools and 52 middle schools from the United States was selected with an unequal probability of selection. Incorporating systematic sampling methods and implicit stratification into the Add Health study design ensures this sample is representative of U.S. schools with respect to region of country, urbanicity, school size, school type, and ethnicity. A total of 20,745 adolescents were personally interviewed in their homes in 1994-1995 (Wave I) and again in 1996 (Wave II; $n=14,738$ ). In 2001-2002 (Wave III), 15,917 of the original Wave I respondents were interviewed in their homes. The respondents are on average 15 years old at Wave I and 22 at Wave III. The full descriptive statistics for all the variables included in the regression analysis below (means, standard deviations, and full correlation matrix) are presented in the Appendix (Table A2).

\section{Dependent Variables}

Alcohol. At Wave III, Add Health asks its respondents four questions about their alcohol consumption. "Think of all the times you have had a drink during the past 12 months. How many drinks did you usually have each time? A "drink" is a glass of wine, a can of beer, a wine cooler, a shot of glass of liquor, or a mixed drink." Respondents' answers range from 0 (if they are not a drinker) to 18 . "During the past 12 months, on how many days did you drink alcohol?" "During the past 12 months, on how many days did you drink five or more drinks in a row?" (Five or more drinks in one sitting is the definition of binge drinking.) "During the past 12 months, on how many days have you been drunk or very high on alcohol?" Respondents answer these three questions on a six-point ordinal scale $(0=$ none, $1=1$ or 2 days in the past 12 months, $2=$ once a month or less ( 3 to 12 times in the past 12 months), $3=2$ or 3 days a month, $4=1$ or 2 days a week, $5=3$ to 5 days a week, $6=$ every day or almost every day).

We perform a factor analysis with the four measures of alcohol consumption. The four measures load on a single latent factor with very high factor loadings (number $=.772$, days $=.883$, binge $=.907$, drunk $=.892$ ). We use the latent factor as the measure of alcohol consumption.

Tobacco. Add Health asks its respondents two questions about their cigarette consumption. "During the past 30 days, on how many days did you smoke cigarettes?" Respondents' answers range from 0 to 30 . "During the past 30 days, on the days you smoked, how many cigarettes did you smoke each day?" Respondents' answers range from 0 (if they are not a smoker) to 100 . We perform a factor analysis with the two measures of tobacco consumption. The two factors load on a single factor with very high factor loadings $($ days $=.931$, number $=.931)$. We use the latent factor as the measure of tobacco consumption.

Drugs. Add Health asks its respondents about their consumption of the following illegal substances: marijuana, cocaine, LSD, crystal meth, and heroin. Add Health asks "During the past 30 days, how many times have you used [the substance]?" We perform a factor analysis with the measures of consumption of five different drugs. The factor analysis produces two factors, with marijuana and cocaine heavily loading on one and LSD and crystal meth heavily loading on the other. We then perform a second-order factor analysis with the two first-order factors. The two factors heavily load on a single factor (factor loadings $=.709, .705$ ). We use the second-order latent factor as the measure of drug consumption.

\section{Independent Variable}

Add Health measures respondents' intelligence with the Peabody Picture Vocabulary Test (PPVT). The raw scores $(0-87)$ are age-standardized and converted to the IQ metric, with a mean of 100 and a standard deviation of 15. Unlike our measure of general intelligence in Study 1, PPVT is properly a measure of verbal intelligence, not general intelligence. However, verbal intelligence is known to be highly correlated with (and thus heavily loads on) general intelligence (Miner, 1957; Wolfle, 1980; Huang \& Hauser, 1998), and PPVT is shown to be a good measure of general intelligence (Stanovich, Cunningham, \& Freeman, 1984; Zagar \& Mead, 1983). In order to establish the direction of causality more clearly, we use the measure of intelligence taken in Wave I (in 1994-1995 when the respondents were in junior high and high school) to predict their adult substance consumption.

\section{Control Variables}

Given that our measure of general intelligence in Study 2 is not as valid as that in Study 1, we control for a larger number of variables in our regression equations in Study 2 to guard against the possibility that our measure of general intelligence may be confounded with something else. 
Demographic variables. We control for age (even though there is very little variance in it given that these are cohort data); sex $(1=$ male); race (with three dummies for Asian, Black, and Native American, with White as the reference category); Hispanicity $(1=$ Hispanic); religion (with four dummies for Catholic, Protestant, Jewish, and other, with none as the reference category); marital status $(1=$ currently married $)$, parenthood $(1=$ parent $)$, education (number of years of formal schooling); earnings (in $\$ 1 \mathrm{~K})$; political attitude $(1=$ very conservative, $2=$ conservative, 3 = middle-of-the-road, $4=$ liberal, $5=$ very liberal); and religiosity ("To what extent are you a religious person?" $0=$ not religious at all, $1=$ slightly religious, $2=$ moderately religious, 3 = very religious). Both political attitudes and religiosity are correlated with intelligence (Kanazawa, 2010a).

Mental health. Because unhappy and stressed individuals may be more likely to use psychoactive drugs, as Study 1 suggests, we control for general satisfaction with life ("How satisfied are you with your life as a whole?" 1 = very dissatisfied, $2=$ dissatisfied, $3=$ neither satisfied nor dissatisfied, 4 = satisfied, 5 = very satisfied); and whether they have taken prescription medication for depression or stress in the last 12 months $(1=$ yes); and whether respondents thought they should get medical care for severe stress, depression, or nervousness but didn't in the last 12 months ( 1 = yes).

Sociality. Because alcohol, tobacco, and drugs are often used as social lubricants and consumed in social settings with others (Becker, 1953), we control for respondents' sociality: Frequency of socialization with friends ("In the past seven days, how many times did you just "hang out" with friends, or talk on the telephone for more than five minutes?" $(0-7))$, and sexual activity (the number of sexual partners in the last 12 months).

Childhood social class. Finally, we control for childhood measures of social class: Family income (in $\$ 1 \mathrm{~K}$ ), mother's education, and father's education (both in years of formal schooling).

\section{Results}

Table 2, first column, shows that, net of age, sex, race, Hispanicity, religion, marital status, parenthood, education, earnings, political attitudes, religiosity, general satisfaction with life, whether taking medication for stress, whether experiencing stress without medication, frequency of socialization with friends, number of sex partners in the last 12 months, childhood family income, mother's education, and father's education, more intelligent individuals consume more alcohol than less intelligent individuals. Add Health respondents who are more intelligent in junior high and high school consume alcohol in larger quantities and more frequently in their early adulthood. This is consistent with the prediction of the Hypothesis.

Men consume more alcohol, whereas Blacks, Asians, and Hispanics consume less relative to Whites. Catholics and liberals consume more alcohol, while those who are married and have children consume less, as do those who are religious and are more satisfied with life in general. More social individuals, who socialize with friends more frequently and have had more recent sex partners, consume more alcohol. Both childhood family income and father's education increase adult alcohol consumption. The equation explains nearly a quarter of the variance in alcohol consumption.

Table 2, second column, shows that, consistent with the prediction of the Hypothesis (and contrary to the negative results in Study 1), more intelligent individuals consume more tobacco than less intelli- gent individuals, net of the same control variables. The more intelligent Add Health respondents are in childhood, the more tobacco they consume in early adulthood. The association of the control variables with tobacco consumption are similar to their association with alcohol consumption. Men and older individuals consume more tobacco, while Blacks, Asians, and Hispanics consume less relative to Whites. Married individuals consume less tobacco while parents consume more. Education and religiosity are negatively associated with tobacco consumption while liberal political attitudes are positively associated with it. Those who are less satisfied with life and are taking medication for stress and depression consume more, although, once again, the direction of causality here is uncertain. As with alcohol, more social individuals, who socialize with friends more frequently and have had more recent sex partners, consume more tobacco.

Table 2, third column, shows that, contrary to the prediction of the Hypothesis (and the results in Study 1), more intelligent individuals do not consume more illegal drugs. Childhood intelligence is not significantly associated with adult drug consumption among Add Health respondents. Men and those who socialize with their friends more frequently consume more illegal drugs, while those who are more educated consume less. None of the other control variables in the equation are significantly associated with the consumption of illegal drugs.

\section{Discussion}

\section{Differences Between NCDS and Add Health}

Our analyses of the two large, nationally representative, and prospectively longitudinal data sets-the National Child Development Study in the United Kingdom and the National Longitudinal Study of Adolescent Health in the United States-partially support the prediction derived from the Savanna-IQ Interaction Hypothesis that more intelligent individuals are more likely to prefer and value the consumption of such evolutionarily novel substances as alcohol, tobacco, and other psychoactive drugs. More intelligent children both in the United Kingdom and the United States grow up to consume alcohol in larger quantities and more frequently in their adult life. Only more intelligent Americans consume significantly more tobacco (while more intelligent Brits consume significantly less). In contrast, only more intelligent Brits consume more illegal drugs (while the positive effect of childhood intelligence on adult consumption of illegal drugs is not statistically significant among Americans). The results for alcohol consumption are consistent, but how can we reconcile the divergent results with respect to tobacco and illegal drugs in the United Kingdom and the United States?

In both surveys, substance use was measured quantitatively as the frequency or quantity of use, so it is unlikely that the differences in survey questions account for the divergent findings. The NCDS and Add Health samples differ in three important respects: nationality, cohort, and age. All NCDS respondents were born in March 1958, whereas the Add Health respondents were born between 1974 and 1983. So Add Health respondents are one generation younger than NCDS respondents. The measures of substance consumption that we use in Study 1 reflect NCDS respondents' behavior throughout their adulthood in their 20s, 30s, and 40s, whereas those that we use in Study 2 reflect Add Health respondents' behavior in their early adulthood in their 20 s. 
Table 2

Associations Between Intelligence and Substance Use National Longitudinal Study of Adolescent Health (United States)

\begin{tabular}{|c|c|c|c|}
\hline & Alcohol & Tobacco & Drugs \\
\hline \multirow[t]{3}{*}{ Childhood intelligence } & $.004^{* * * * *}$ & $.003^{* *}$ & .001 \\
\hline & $(.001)$ & $(.001)$ & $(.001)$ \\
\hline & .058 & .036 & .012 \\
\hline \multicolumn{4}{|l|}{ Demographic variables } \\
\hline \multirow[t]{3}{*}{ Age } & .001 & $.032^{* * * *}$ & .015 \\
\hline & $(.007)$ & $(.007)$ & $(.010)$ \\
\hline & .001 & .055 & .020 \\
\hline \multirow[t]{3}{*}{ Sex } & $.403^{* * * * *}$ & $.161^{* * * *}$ & $.110^{\text {***** }}$ \\
\hline & $(.022)$ & $(.023)$ & $(.033)$ \\
\hline & .199 & .080 & .042 \\
\hline \multicolumn{4}{|l|}{ Race } \\
\hline \multirow{3}{*}{ Asian } & $-.391^{* * * *}$ & $-.213^{* * *}$ & .026 \\
\hline & $(.043)$ & $(.044)$ & $(.063)$ \\
\hline & -.099 & -.054 & .005 \\
\hline \multirow[t]{3}{*}{ Black } & $-.518^{* * * * *}$ & $-.432^{* * * *}$ & -.038 \\
\hline & $(.033)$ & $(.034)$ & $(.049)$ \\
\hline & -.183 & -.152 & -.010 \\
\hline \multirow[t]{3}{*}{ Native American } & .022 & -.038 & -.044 \\
\hline & $(.050)$ & $(.052)$ & $(.074)$ \\
\hline & .005 & -.008 & -.007 \\
\hline \multirow[t]{3}{*}{ Hispanicity } & $-.237^{* * * *}$ & $-.355^{* * * *}$ & -.012 \\
\hline & $(.035)$ & $(.036)$ & $(.052)$ \\
\hline & -.081 & -.123 & -.003 \\
\hline \multicolumn{4}{|l|}{ Religion } \\
\hline \multirow[t]{3}{*}{ Catholic } & $.172^{\text {****** }}$ & -.046 & -.092 \\
\hline & $(.036)$ & $(.037)$ & $(.053)$ \\
\hline & .075 & -.020 & -.031 \\
\hline \multirow[t]{3}{*}{ Protestant } & -.020 & -.001 & -.104 \\
\hline & $(.041)$ & $(.043)$ & $(.061)$ \\
\hline & -.007 & .000 & -.029 \\
\hline \multirow[t]{3}{*}{ Jewish } & -.015 & -.217 & -.076 \\
\hline & $(.120)$ & $(.125)$ & $(.177)$ \\
\hline & -.001 & -.020 & -.005 \\
\hline \multirow[t]{3}{*}{ Other } & .012 & -.002 & -.056 \\
\hline & $(.035)$ & $(.036)$ & $(.052)$ \\
\hline & .006 & -.001 & -.021 \\
\hline \multirow[t]{3}{*}{ Marital status } & $-.169^{* * * *}$ & $-.071^{*}$ & -.055 \\
\hline & $(.032)$ & $(.034)$ & $(.048)$ \\
\hline & -.063 & -.027 & -.016 \\
\hline \multirow[t]{3}{*}{ Parenthood } & $-.141^{* * * * *}$ & $.141^{* * * *}$ & -.046 \\
\hline & $(.033)$ & $(.034)$ & $(.048)$ \\
\hline & -.052 & .052 & -.013 \\
\hline Education & .002 & $-.135^{* * *}$ & $-.045^{\text {**** }}$ \\
\hline & $(.007)$ & $(.007)$ & $(.010)$ \\
\hline & .004 & -.261 & -.067 \\
\hline Earnings & .001 & .001 & .000 \\
\hline & $(.001)$ & $(.001)$ & $(.001)$ \\
\hline & .009 & .010 & -.008 \\
\hline Political attitude & $.100^{* * * * *}$ & $.052^{* * * *}$ & .041 \\
\hline & $(.015)$ & $(.015)$ & $(.022)$ \\
\hline & .076 & .039 & .024 \\
\hline Religiosity & $-.130^{* * * *}$ & $-.078^{* * * *}$ & -.025 \\
\hline & $(.014)$ & $(.015)$ & $(.021)$ \\
\hline & -.117 & -.070 & -.017 \\
\hline Mental health & & & \\
\hline General life satisfaction & $-.071^{* * * * *}$ & $-.121^{* * * *}$ & -.024 \\
\hline & $(.014)$ & $(.015)$ & $(.021)$ \\
\hline & -.055 & -.093 & -.014 \\
\hline Medication for stress & .076 & $.215^{* * *}$ & .076 \\
\hline & $(.050)$ & $(.052)$ & $(.074)$ \\
\hline & .016 & .047 & $\begin{array}{c}.013 \\
\text { continues }\end{array}$ \\
\hline
\end{tabular}


Table 2 (continued)

\begin{tabular}{lccc}
\hline & Alcohol & Tobacco & Drugs \\
\hline Stress but no medical help & .055 & .109 & -.007 \\
& $(.058)$ & $.061)$ & $.086)$ \\
Sociality & .010 & .020 & .000 \\
Frequency of socialization with friends & $.062^{* * * *}$ & $.040^{* * * *}$ & $.023^{* * *}$ \\
& $(.005)$ & $(.005)$ & $.007)$ \\
Number of sex partners in 12 months & .141 & .091 & .040 \\
& $.078^{* * * *}$ & $.035^{* * * *}$ & .014 \\
& $(.005)$ & $.005)$ & $.008)$ \\
Childhood social class & .159 & .073 & .021 \\
Childhood family income & & & $-1.310^{-5}$ \\
& $.001^{*}$ & -.000 & $(.000)$ \\
Mother's education & $. .000)$ & $.000)$ & .000 \\
& .027 & -.023 & .000 \\
Father's education & .004 & -.011 & $(.011)$ \\
& $(.007)$ & $(.008)$ & .000 \\
Constant & .008 & -.021 & .009 \\
& $.018^{* * *}$ & .000 & $(.010)$ \\
$R^{2}$ & $(.007)$ & $(.007)$ & .014 \\
Number of cases & .037 & -.002 & .072 \\
& -.759 & 1.227 & $(.276)$ \\
\end{tabular}

Note. Main entries are unstandardized regression coefficients. Numbers in parentheses are standard errors. Numbers in italics are standardized coefficients

${ }^{*} p<.05 . \quad{ }^{* *} p<.01 .{ }^{* * * *} p<.001$.

Note that previous studies of American samples find a positive effect of intelligence on smoking (Johnson et al., 2009), while those of British samples find a negative effect (Batty et al., 2007; Batty, Deary, \& Macintyre, 2007). So this appears to be a consistent and replicable national difference between the United States and the United Kingdom.

Among the possible cultural differences, the public antismoking campaign has been far more aggressive and blatant in the United Kingdom than in the United States. For example, in the United States, each pack of cigarettes carries the Surgeon General's warning ("Smoking causes lung cancer, heart disease, emphysema, and may complicate pregnancy") in small print, on the side of the package. In the United Kingdom, the warnings are more blatant ("Smoking kills," "Smoking can cause a slow and painful death," "Smoking may reduce the blood flow and causes impotence," "Smokers die younger") in extremely large print, in front of the package. Conversely, public campaigns against drug use may have been stronger in the United States ("Just say no") than in the United Kingdom Because government warnings and public campaigns are themselves evolutionarily novel, more intelligent individuals may be more likely to respond to them than less intelligent individuals. The divergent results with respect to tobacco and illegal drugs may therefore reflect the social and cultural differences between the United Kingdom and the United States, the generational differences between the 1950s and 1970s/80s, or the age differences between the NCDS and the Add Health respondents, or any combination of the three.

This study is among the first to examine the effect of childhood intelligence on adult consumption of alcohol and tobacco, and, to our knowledge, the very first to examine its effect on the consump- tion of illegal drugs. And this is the first study to examine the effect of substance use in two different countries. There is therefore currently insufficient information to account for the divergent findings in Studies 1 and 2 with respect to tobacco and drugs use. Further comparative research is necessary, first, to replicate the results of our analyses above, and, second, to explain the divergent patterns in the United Kingdom and the United States if shown to be robust.

\section{General Intelligence, Substance Use, and Health}

Our results that more intelligent individuals are more likely to consume alcohol, tobacco, and drugs may at first sight be paradoxical. There has been ample evidence in the emerging field of cognitive epidemiology that more intelligent individuals live longer and stay healthier (Batty, Deary, \& Gottfredson, 2007; Deary, Whiteman, Starr, Whalley, \& Fox, 2004; Kanazawa, 2006), although it is not known exactly why (Deary, 2008; Gottfredson \& Deary, 2004). Since it is universally agreed that the consumption of alcohol, tobacco, and drugs is detrimental to health and longevity, how is it that more intelligent individuals are simultaneously more likely to consume these substances yet stay healthier and live longer?

For example, in the NCDS data, self-perceived health throughout adulthood is significantly positively correlated with childhood general intelligence $(r=.218, p<.001, n=4,427)$. Selfperceived health is also positively associated with frequency $(r=$ $.151, p<.001, n=7,055)$ and quantity $(r=.055, p<.001$, $n=7,014)$ of alcohol consumption, but is negatively associated with the consumption of tobacco $(r=-.262, p<.001, n=7,004)$ and drugs $(r=-.092, p<.001, n=7,018)$. If we regress self-perceived health on childhood general intelligence, frequency 
of alcohol consumption, quantity of alcohol consumption, tobacco consumption, and drugs consumption in a linear multiple regression equation, intelligence $(b=.011, p<.001$, standardized coefficient $=.147)$ and the frequency of alcohol consumption $(b=$ $.128, p<.001$, standardized coefficient $=.127$ ) are significantly positively associated with self-perceived health, while the consumption of tobacco $(b=-.220, p<.001$, standardized coefficient $=-.217)$ and drugs $(b=-.084, p<.001$, standardized coefficient $=-.069$ ) are significantly negatively associated with it. Net of other variables in the model, the quantity of alcohol consumption is no longer significantly associated with selfperceived health $(b=-.011, n s$, standardized coefficient $=$ -.011 ), probably because it is highly correlated with the frequency of consumption ( $r=.582, p<.001, n=8,484)$.

The relationships among general intelligence, substance use, and health appear to be highly intricate, if quite modest in each bivariate association. Further research is necessary to explicate the exact nature, magnitude and direction of their relationships.

\section{Conclusion}

The Savanna-IQ Interaction Hypothesis suggests that more intelligent individuals may be more likely to acquire and espouse evolutionarily novel values and preferences than less intelligent individuals, while general intelligence may have no effect on the acquisition and espousal of evolutionarily familiar values and preferences. Given that psychoactive substances, including alcohol, tobacco, and drugs, are all evolutionarily novel, having become available for regular human consumption in the last 10,000 years or less, the Hypothesis would predict that more intelligent individuals are more likely to acquire a preference for the consumption of such substances.

Our analysis of the National Child Development Study (NCDS) in the United Kingdom and the National Longitudinal Study of Adolescent Health (Add Health) in the United States partially support our prediction derived from the Hypothesis. More intelligent children grow up to consume alcohol more frequently and in larger quantities both in the United Kingdom and the United States. More intelligent children grow up to consume more tobacco in the United States, but not in the United Kingdom. More intelligent children grow up to consume more illegal drugs in the United Kingdom, but not in the United States.

What other substances might more intelligent individuals be more likely to prefer to consume? Given that the human consumption of coffee is even more recent in origin than that of alcohol and tobacco (Smith, 1999), traced to Ethiopia in the 9th century AD (Pendergrast, 1999), we would expect that more intelligent individuals consume more coffee than less intelligent individuals. Among the Wave I respondents of Add Health, those who usually have coffee or tea for breakfast on weekday mornings $(n=1,244)$ have a significantly (albeit slightly) higher intelligence than those who don't ( $n=18,458$; 99.5 vs. $\left.98.5, t_{19700}=2.233, p<.05\right)$. Net of the same control variables as in Table 2 , childhood intelligence is marginally significantly positively associated with the consumption of coffee or tea for breakfast on weekday mornings in a binary logistic regression analysis $(b=.007, p=.089)$. One standard deviation increase in childhood intelligence increases the odds of caffeine consumption by $11 \%$.

At the same time, humans are naturally omnivorous, and anyone who eschewed animal protein and ate only vegetables in the ancestral environment, in the face of food scarcity and precariousness of its supply, was not likely to have survived long and stayed healthy enough to become our ancestors. So we would expect that vegetarianism as a value is evolutionarily novel, and the Hypothesis would predict that more intelligent individuals are more likely to become vegetarian. At least one study (Gale, Deary, Schoon, \& Batty, 2007) confirms this prediction in the United Kingdom, and the Add Health data replicate Gale et al.'s (2007) finding in the United States (Kanazawa, 2010a).

\section{References}

Ackerman, P. L., \& Heggestad, E. D. (1997). Intelligence, personality, and interests: Evidence for overlapping traits. Psychological Bulletin, 121, 219-245.

Alexander, R. D., Hoogland, J. L., Howard, R. D., Noonan, K. M., \& Sherman, P. W. (1979). Sexual dimorphisms and breeding systems in pinnipeds, ungulates, primates and humans. In N. A. Chagnon, \& W. Irons (Eds.), Evolutionary biology and human social behavior: An anthropological perspective (pp. 402-435). North Scituate: Duxbury Press.

Atran, S. (2002). In gods we trust: The evolutionary landscape of religion. Oxford: Oxford University Press.

Batty, G. D., Deary, I. J., \& Gottfredson, L. S. (2007). Premorbid (early life) IQ and later mortality risk: Systematic review. Annals of Epidemiology, 17, 278-288.

Batty, G. D., Deary, I. J., \& Macintyre, S. (2007). Childhood IQ in relation to risk factors for premature mortality in middle-aged persons: The Aberdeen Children of the 1950s study. Journal of Epidemiology and Community Health, 61, 241-247.

Batty, G. D., Deary, I. J., Schoon, I., Emslie, C., Hunt, K., \& Gale, C. R. (2008). Childhood mental ability and adult alcohol intake and alcohol problems: The 1970 British Cohort Study. American Journal of Public Health, 98, 2237-2243.

Batty, G. D., Deary, I. J., Schoon, I., \& Gale, C. R. (2007). Mental ability across childhood in relation to risk factors for premature mortality in adult life: The 1970 British Cohort Study. Journal of Epidemiology and Community Health, 61, 997-1003.

Becker, H. S. (1953). Becoming a marihuana user. American Journal of Sociology, 59, 235-242.

Boyer, P. (2001). Religion explained: The evolutionary origins of religious thought. New York: Basic.

Brownstein, M. J. (1993). A brief history of opiates, opioid peptides, and opioid receptors. Proceedings of the National Academy of Sciences, USA, 90, 5391-5393.

Crawford, C. B. (1993). The future of sociobiology: Counting babies or proximate mechanisms? Trends in Ecology and Evolution, 8, 183-186.

Deary, I. J. (2008). Why do intelligent people live longer? Nature, 456, $175-176$.

Deary, I. J., Batty, G. D., \& Gale, C. R. (2008). Bright children become enlightened adults. Psychological Science, 19, 1-6.

Deary, I. J., Whiteman, M. C., Starr, J. M., Whalley, L. J., \& Fox, H. C. (2004). The impact of childhood intelligence on later life: Following up the Scottish Mental Surveys of 1932 and 1947. Journal of Personality and Social Psychology, 86, 130-147.

de Waal, F. B. M. (1989). Food sharing and reciprocal obligations among chimpanzees. Journal of Human Evolution, 18, 433-459.

de Waal, F. B. M. (1992). Appeasement, celebration, and food sharing in the two Pan species. In Nishida, T., McGrew, W. C., \& Marler, P. (Eds.), Topics in primatology: Human origins (pp. 37-50). Tokyo: University of Tokyo Press.

de Waal, F. B. M., Luttrell, L. M., \& Canfield, M. E. (1993). Preliminary data on voluntary food sharing in brown capuchin monkeys. American Journal of Primatology, 29, 73-78.

Dudley, R. (2000). Evolutionary origins of human alcoholism in primate frugivory. Quarterly Review of Biology, 75, 3-15. 
Ellis, L. (1998). Neodarwinian theories of violent criminality and antisocial behavior: Photographic evidence from nonhuman animals and a review of the literature. Aggression and Violent Behavior, 3, 61-110.

Gale, C. R., Deary, I. J., Schoon, I., \& Batty, G. D. (2007). IQ in childhood and vegetarianism in adulthood: 1970 British Cohort Study. British Medical Journal, 334, 245-248.

Goodman, J. (1993). Tobacco in history: The cultures of dependence. London: Routledge.

Goodspeed, T. H. (1954). The genus Nicotiana. Waltham: Chronica Botanica.

Gottfredson, L. S., \& Deary, I. J. (2004). Intelligence predicts health and longevity, but why? Current Directions in Psychological Science, 13, 1-4.

Guthrie, S. E. (1993). Faces in the clouds: A new theory of religion. New York: Oxford University Press.

Harvey, P. H., \& Bennett, P. M. (1985). Sexual dimorphism and reproductive strategies. In J. Ghesquiere, R. D. Martin, \& F. Newcombe (Eds.), Human sexual dimorphism (pp. 43-59). London: Taylor and Francis.

Haselton, M. G., \& Nettle, D. (2006). The paranoid optimist: An integrative evolutionary model of cognitive biases. Personality and Social Psychology Review, 10, 47-66.

Herrnstein, R. J., \& Murray, C. (1994). The bell curve: Intelligence and class structure in American life. New York: Free Press.

Holmstedt, B., \& Fredga, A. (1981). Sundry episodes in the history of coca and cocaine. Journal of Ethnopharmacology, 3, 113-147.

Huang, M.-H., \& Hauser, R. M. (1998). Trends in black-white test-score differentials: II. The WORDSUM vocabulary test. In U. Neisser (Ed.), The rising curve: Long-term gains in $I Q$ and related measure (pp. 303-332). Washington DC: American Psychological Association.

Johnson, W., Hicks, B. M., McGue, M., \& Iacono, W. G. (2009). How intelligence and education contribute to substance use: Hints from the Minnesota Twin family study. Intelligence, 37, 613-624.

Kanazawa, S. (2001). De gustibus est disputandum. Social Forces, 79, $1131-1163$

Kanazawa, S. (2002). Bowling with our imaginary friends. Evolution and Human Behavior, 23, 167-171.

Kanazawa, S. (2004a). The Savanna Principle. Managerial and Decision Economics, 25, 41-54.

Kanazawa, S. (2004b). General intelligence as a domain-specific adaptation. Psychological Review, 111, 512-523.

Kanazawa, S. (2006). Mind the gap. . . in intelligence: Reexamining the relationship between inequality and health. British Journal of Health Psychology, 11, 623-642.

Kanazawa, S. (2008). Temperature and evolutionary novelty as forces behind the evolution of general intelligence. Intelligence, 36, 99-108.

Kanazawa, S. (2009). Evolutionary psychology and crime. In A. Walsh, \& K. M. Beaver (Eds.), Biosocial criminology: New directions in theory and research (pp. 90-110). New York: Routledge.

Kanazawa, S. (2010a). Why liberals and atheists are more intelligent. Social Psychology Quarterly, 73, 33-57.

Kanazawa, S. (2010b). Evolutionary psychology and intelligence research. American Psychologist, 65, 279-289.

Kanazawa, S., \& Novak, D. L. (2005). Human sexual dimorphism in size may be triggered by environmental cues. Journal of Biosocial Science, 37, 657-665.

Kanazawa, S., \& Perina, K. (2009). Why night owls are more intelligent. Personality and Individual Differences, 47, 685-690.

Kirkpatrick, L. A. (2005). Attachment, evolution, and the psychology of religion. New York: Guilford Press.
Kluegel, J. R., \& Smith, E. R. (1986). Beliefs about inequality: Americans' view of what is and what ought to be. New York: Aldine.

Lake, C. C., \& Breglio, V. J. (1992). Different voices, different views: The politics of gender. In P. Ries, \& A. J. Stone (Eds.), The American woman, 1992-93: A status report (pp. 178-201). New York: Norton.

Leutenegger, W., \& Kelly, J. T. (1977). Relationship of sexual dimorphism in canine size and body size to social, behavioral, and ecological correlates in anthropoid primates. Primates, 18, 117-136.

Miller, A. S., \& Hoffmann, J. P. (1995). Risk and religion: An explanation of gender differences in religiosity. Journal for the Scientific Study of Religion, 34, 63-75.

Miller, A. S., \& Stark, R. (2002). Gender and religiousness: Can socialization explanations be saved? American Journal of Sociology, 107, 1399-1423.

Miner, J. B. (1957). Intelligence in the United States: A survey-with conclusions for manpower utilization in education and employment. New York: Springer.

Pendergrast, M. (1999). Uncommon grounds: The history of coffee and how it transformed our world. New York: Basic Books.

Pickford, M. (1986). On the origins of body size dimorphism in primates. In M. Pickford, \& B. Chiarelli (Eds.), Sexual dimorphism in living and fossil primates (pp. 77-91). Florence, Italy: Il Sedicesimo.

Raine, A., Reynolds, C., Venables, P. H., \& Mednick, S. A. (2002). Stimulation seeking and intelligence: A prospective longitudinal study. Journal of Personality and Social Psychology, 82, 663-674.

Shapiro, R. Y., \& Mahajan, H. (1986). Gender differences in policy preferences: A summary of trends from the 1960s to the 1980s. Public Opinion Quarterly, 50, 42-61.

Smith, E. O. (1999). Evolution, substance abuse, and addiction. In W. R. Trevathan, E. O. Smith, \& J. J. McKenna (Eds.), Evolutionary Medicine (pp. 375-405). New York: Oxford University Press.

Stanovich, K. E., Cunningham, A. E., \& Feeman, D. J. (1984). Intelligence, cognitive skills, and early reading progress. Reading Research Quarterly, 19, 278-303.

Sundquist, J. L. (1983). Dynamics of the party system (rev. ed.). Washington DC: Brookings Institution.

Symons, D. (1990). Adaptiveness and adaptation. Ethology and Sociobiology, 11, 427-444.

Tooby, J., \& Cosmides, L. (1990). The past explains the present: Emotional adaptations and the structure of ancestral environments. Ethology and Sociobiology, 11, 375-424.

Vaillant, G. E. (1995). The natural history of alcoholism revisited. Cambridge, MA: Harvard University Press.

Vallee, B. L. (1998). Alcohol in the western world. Scientific American, $278,80-85$

Wilbert, J. (1991). Does pharmacology corroborate the nicotine therapy and practices of South American shamanism? Journal of Ethnopharmacology, 32, 179-186.

Wilson, J. Q., \& Herrnstein, R. J. (1985). Crime and human nature: The definitive study of the causes of crime. New York: Touchstone.

Wirls, D. (1986). Reinterpreting the gender gap. Public Opinion Quarterly, 50, 316-330.

Wolfle, L. M. (1980). The enduring effects of education on verbal skills. Sociology of Education, 53, 104-114.

Zagar, R., \& Mead, J. D. (1983). Analysis of short test battery for children. Journal of Clinical Psychology, 39, 590-597. 


\section{Appendix}

\section{Descriptive Statistics}

Table A1

Descriptive Statistics National Child Development Study (United Kingdom)

\begin{tabular}{|c|c|c|c|c|c|c|c|c|c|c|}
\hline & (1) & (2) & (3) & (4) & (5) & (6) & (7) & (8) & (9) & (10) \\
\hline \multicolumn{11}{|l|}{ (1) } \\
\hline (2) & $.582^{* * * *}$ & & & & & & & & & \\
\hline (3) & -.003 & $.103^{* * * *}$ & & & & & & & & \\
\hline (4) & $.116^{* * * *}$ & $.160^{* * * *}$ & $.153^{* * * *}$ & & & & & & & \\
\hline (5) & $.229^{* * * * *}$ & $.136^{* * * * *}$ & $-.213^{* * * *}$ & $.064^{* * * * *}$ & & & & & & \\
\hline (6) & $.304^{* * * * *}$ & $.167^{* * * * *}$ & $.027^{*}$ & $.110^{* * * * *}$ & -.001 & & & & & \\
\hline (7) & .008 & .000 & $.030^{*}$ & -.006 & $-.029^{*}$ & $-.038^{* * * * *}$ & & & & \\
\hline (8) & $-.029^{* *}$ & $-.042^{* * * *}$ & $-.054^{* * * * *}$ & $-.080^{* * * *}$ & $-.032^{\text {*** }}$ & $-.125^{* * * *}$ & $-.254^{\text {***** }}$ & & & \\
\hline (9) & $-.061^{* * * *}$ & $-.042^{* * * *}$ & $-.046^{* * * *}$ & $-.033^{* *}$ & $.084^{* * * *}$ & $-.049^{* * * *}$ & $-.133^{\text {***** }}$ & $-.272^{* * * *}$ & & \\
\hline (10) & $-.112^{* * * *}$ & $-.054^{* * * *}$ & $-.028^{*}$ & $.021^{*}$ & $.031^{* * *}$ & $.018^{*}$ & $-.041^{* * * *}$ & $-.084^{* * * *}$ & $-.044^{* * *}$ & \\
\hline (11) & $-.107^{* * * *}$ & $-.086^{* * * *}$ & $-.126^{* * * *}$ & $-.099^{* * * *}$ & $.099^{* * * *}$ & $-.147^{* * *}$ & $.365^{* * * *}$ & $.246^{* * * *}$ & $.327^{* * * *}$ & $.108^{* * *}$ \\
\hline (12) & $-.179^{* * * *}$ & $-.132^{* * * *}$ & $.026^{*}$ & $-.113^{* * * *}$ & $-.136^{* * *}$ & $-.197^{* * * *}$ & -.013 & $.095^{* * * *}$ & .001 & $-.018 *$ \\
\hline (13) & $-.181^{* * * *}$ & $-.125^{* * *}$ & $.045^{\text {***** }}$ & $-.102^{* * *}$ & $-.147^{* * * *}$ & $-.209^{* * * *}$ & -.011 & $.094^{* * * * *}$ & -.003 & $-.022 *$ \\
\hline (14) & $-.223^{* * * *}$ & $-.124^{* * * *}$ & $.194^{* * * * *}$ & $-.021^{*}$ & $-.272^{* * * *}$ & $-.186^{* * * * *}$ & .006 & $.023^{* * *}$ & $-.038^{* * * *}$ & .006 \\
\hline (15) & $.125^{* * * *}$ & $.069^{* * * * *}$ & $-.140^{* * * * *}$ & $.025^{* * *}$ & $.381^{* * * * * *}$ & .005 & -.002 & $-.022^{*}$ & $.044^{* * * *}$ & $.029^{* * *}$ \\
\hline (16) & $.242^{* * * *}$ & $.139^{* * * *}$ & $-.074^{* * * *}$ & $-.034^{* * *}$ & $.149^{* * * * *}$ & $.351^{\text {***** }}$ & -.010 & $-.021^{*}$ & -.008 & -.008 \\
\hline (17) & $-.043^{* * * *}$ & -.014 & $.067^{* * * * *}$ & $.039^{* * * *}$ & $-.032^{* * *}$ & $-.065^{* * * *}$ & .002 & $-.026^{* * *}$ & .013 & .013 \\
\hline (18) & .016 & -.016 & $-.151^{* * * *}$ & $-.119^{* * *}$ & $.061^{* * * * *}$ & $-.050^{* * * *}$ & .013 & $.031^{* *}$ & $.049^{* * * *}$ & -.016 \\
\hline (19) & $.114^{* * * *}$ & $.075^{* * * *}$ & $-.133^{* * * *}$ & .018 & $.310^{* * * *}$ & .005 & $-.066^{* * * *}$ & $.046^{* * * * *}$ & $.045^{* * * *}$ & .017 \\
\hline (20) & $.125^{* * *}$ & $.087^{* * * *}$ & $-.046^{* * * *}$ & $.069^{\text {***** }}$ & $.291^{* * * *}$ & $-.025^{* * *}$ & $-.021^{*}$ & .004 & .015 & -.012 \\
\hline (21) & $.125^{* * * *}$ & $.105^{* * * *}$ & $-.081^{* * * *}$ & $.050^{* * * * *}$ & $.313^{* * * *}$ & -.013 & $-.026^{*}$ & -.007 & .019 & $.041^{\text {**** }}$ \\
\hline mean & .000 & .000 & .000 & .000 & 100.000 & .517 & .111 & .341 & .125 & .013 \\
\hline$S D$ & 1.000 & 1.000 & 1.000 & 1.000 & 15.000 & .500 & .314 & .474 & .331 & .115 \\
\hline
\end{tabular}

Note. $\quad(1)=$ alcohol frequency; $(2)=$ alcohol quantity; $(3)=$ tobacco; $(4)=\operatorname{drugs} ;(5)=$ childhood general intelligence; $(6)=$ sex; $(7)=$ Catholic; $(8)=$ Anglican; (9) = other Christian; (10) = other religion; (11) = frequency of church attendance; $(12)=$ currently married; (13) = ever married; (14) = number of children; (15) = education; (16) = earnings; (17) = depression; (18) = satisfaction with life; (19) = social class at birth; (20) = mother's education; $(21)=$ father's education.

${ }^{*} p<.05 .{ }^{* * *} p<.01 .{ }^{* * * *} p<.001$. 


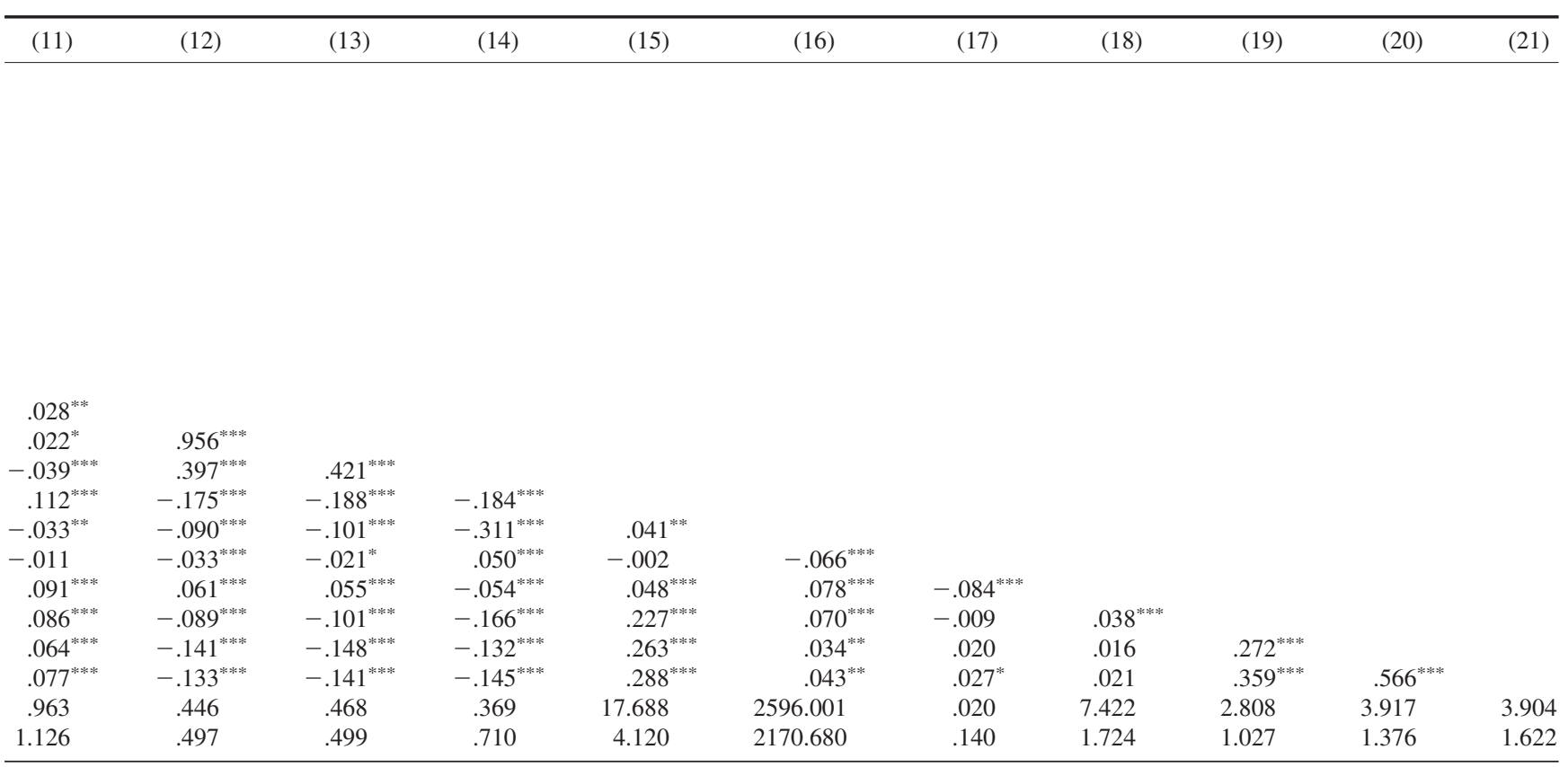

(Appendix continues) 
Table A2

Descriptive Statistics National Longitudinal Study of Adolescent Health (United States)

\begin{tabular}{|c|c|c|c|c|c|c|c|c|c|c|c|c|c|c|}
\hline & (1) & (2) & (3) & (4) & (5) & (6) & (7) & (8) & (9) & (10) & (11) & (12) & (13) & (14) \\
\hline \multicolumn{15}{|l|}{ (1) } \\
\hline (2) & $.263^{* * * *}$ & & & & & & & & & & & & & \\
\hline (3) & $.091^{* * * *}$ & $.125^{* * * *}$ & & & & & & & & & & & & \\
\hline (4) & $.232^{* * * *}$ & $.058^{* * * *}$ & $.024^{* * *}$ & & & & & & & & & & & \\
\hline (5) & $-.030^{* * * *}$ & $-.019^{*}$ & -.015 & $-.077^{* * * *}$ & & & & & & & & & & \\
\hline (6) & $.215^{* * * *}$ & $.082^{* * * * *}$ & $.062^{* * * *}$ & $.045^{* * * *}$ & $.056^{* * * *}$ & & & & & & & & & \\
\hline (7) & $-.050^{* * * *}$ & $-.055^{* * * *}$ & -.008 & $-.032^{* * * *}$ & $.054^{* * * *}$ & $.027^{* * * *}$ & & & & & & & & \\
\hline (8) & $-.229^{* * * *}$ & $-.160^{* * * * *}$ & -.014 & $-.235^{* * * * *}$ & $-.023^{* * *}$ & $-.037^{* * * * *}$ & $-.148^{* * * *}$ & & & & & & & \\
\hline (9) & .004 & .000 & .002 & $-.073^{* * * *}$ & .013 & $.020^{*}$ & $-.053^{* * *}$ & $-.067^{* * * *}$ & & & & & & \\
\hline (10) & $-.061^{* * * *}$ & $-.111^{* * *}$ & -.009 & $-.196^{* * * *}$ & $.082^{* * * *}$ & $.020^{*}$ & $-.051^{* * *}$ & $-.177^{* * * *}$ & $.195^{* * * *}$ & & & & & \\
\hline (11) & $.069^{* * * *}$ & $-.036^{* * * *}$ & -.008 & $-.062^{* * * *}$ & $.063^{* * * *}$ & .003 & $.100^{* * * *}$ & $-.236^{* * * *}$ & $.056^{* * * *}$ & $.339^{* * * *}$ & & & & \\
\hline (12) & $-.054^{* * * *}$ & -.010 & $-.028^{* * * * *}$ & $.023^{* *}$ & $-.019^{*}$ & $-.027^{* * * *}$ & $-.078^{* * * *}$ & $.086^{* * * *}$ & $-.043^{* * * * *}$ & $-.148^{* * * *}$ & $-.236^{* * * *}$ & & & \\
\hline (13) & $.031^{* * * * *}$ & $-.026^{* * *}$ & -.003 & $.055^{\text {***** }}$ & -.001 & -.007 & $-.023^{* *}$ & $-.036^{* * * *}$ & -.014 & $-.023^{* *}$ & $-.049^{* * * *}$ & $-.035^{* * * * *}$ & & \\
\hline (14) & $-.080^{* * * *}$ & $-.029^{* * * *}$ & -.007 & $-.032^{* * * *}$ & $-.045^{* * * *}$ & $-.031^{* * * *}$ & $-.035^{* * * *}$ & $.206^{* * * *}$ & $-.035^{\text {**** }}$ & $-.157^{* * * *}$ & $-.468^{* * * *}$ & $-.333^{* * * *}$ & $-.070^{* * * *}$ & \\
\hline (15) & $-.144^{* * * *}$ & .000 & $-.037^{* * * *}$ & $-.019^{* * *}$ & $.210^{* * * *}$ & $-.084^{* * * *}$ & $-.042^{* * * *}$ & $-.105^{* * * *}$ & .009 & $.059^{* * * * *}$ & $-.028^{* * * *}$ & $.045^{* * * *}$ & $-.024^{* * *}$ & $.042^{\text {******* }}$ \\
\hline (16) & $-.153^{* * * *}$ & $.071^{* * * * *}$ & $-.022^{* *}$ & $-.089^{* * * *}$ & $.147^{* * * *}$ & $-.146^{* * * *}$ & $-.059^{* * * *}$ & $.069^{* * * * *}$ & $.029^{* * * * *}$ & $.036^{* * * *}$ & $-.033^{* * * *}$ & $.018^{*}$ & $-.033^{* * * *}$ & $.026^{* * *}$ \\
\hline (17) & $.082^{* * * *}$ & $-.233^{* * * *}$ & $-.050^{* * * *}$ & $.332^{* * * *}$ & $.181^{* * * *}$ & $-.074^{* * * *}$ & $.107^{* * * *}$ & $-.055^{* * * *}$ & $-.076^{* * * *}$ & $-.085^{* * * *}$ & $.045^{\text {***** }}$ & $.028^{* * * *}$ & $.076^{* * * *}$ & -.011 \\
\hline (18) & $.046^{* * * *}$ & $.021^{*}$ & -.003 & $.039^{* * * *}$ & $.211^{* * * *}$ & $.108^{* * * *}$ & .008 & $-.064^{* * * *}$ & .016 & .013 & $.043^{* * * *}$ & -.016 & -.004 & $-.041^{* * * * *}$ \\
\hline (19) & $.120^{* * * *}$ & $.043^{* * * *}$ & $.031^{* * * *}$ & $.135^{* * * *}$ & $-.026^{* *}$ & $-.044^{* * * *}$ & -.006 & -.008 & .004 & .001 & -.011 & $-.077^{* * * *}$ & $.077^{* * * *}$ & $-.054^{* * * *}$ \\
\hline (20) & $-.196^{* * * *}$ & $-.144^{* * * *}$ & $-.059^{* * * *}$ & $-.118^{* * * *}$ & .003 & $-.084^{* * * *}$ & $-.021^{*}$ & $.179^{* * * *}$ & $-.025^{* * *}$ & .010 & .015 & $.145^{* * * *}$ & $-.019^{*}$ & $.272^{* * * *}$ \\
\hline (21) & $-.066^{* * * *}$ & $-.125^{* * * *}$ & $-.047^{* * * *}$ & .014 & .001 & .000 & $-.024^{* *}$ & $-.064^{* * * *}$ & $-.029^{* * * *}$ & .006 & $.029^{* * * *}$ & $.055^{* * * *}$ & $.016^{*}$ & .005 \\
\hline (22) & $.040^{* * * * *}$ & $.089^{* * * * *}$ & $.024^{* * *}$ & $.058^{* * * * *}$ & -.014 & $-.093^{* * * *}$ & $-.047^{* * * *}$ & $-.068^{* * * *}$ & -.008 & $-.039^{* * * *}$ & $-.024^{* * *}$ & -.009 & .010 & .001 \\
\hline (23) & $.033^{* * * * *}$ & $.051^{* * * *}$ & $.025^{* * *}$ & $.030^{* * * * *}$ & -.007 & $-.048^{* * * *}$ & $-.021^{*}$ & $-.016^{*}$ & $.035^{* * * * *}$ & .012 & -.005 & -.002 & $-.017^{*}$ & -.004 \\
\hline (24) & $.204^{* * * * *}$ & $.062^{* * * * *}$ & $.055^{* * * * *}$ & $.120^{* * * * *}$ & $-.160^{* * * *}$ & $-.023^{* * *}$ & $-.023^{* * *}$ & $.025^{* * *}$ & $-.030^{* * * * *}$ & $-.092^{* * * * *}$ & $-.020^{*}$ & $-.017^{*}$ & $.027^{* * * *}$ & $.037^{* * * * *}$ \\
\hline (25) & $.196^{* * * *}$ & $.102^{* * * * *}$ & $.051^{* * * *}$ & -.004 & $-.019^{*}$ & $.090^{* * * * *}$ & $-.056^{* * * *}$ & $.084^{* * * *}$ & .009 & $-.031^{* * * *}$ & $-.022^{* * *}$ & -.012 & -.011 & .009 \\
\hline (26) & $.126^{* * * *}$ & $-.037^{* * * *}$ & .000 & $.213^{* * * *}$ & -.007 & .000 & $.037^{* * * *}$ & $-.126^{* * * *}$ & $-.051^{* * * *}$ & $-.094^{* * * *}$ & .013 & .011 & $.118^{* * * *}$ & $-.045^{\text {**** }}$ \\
\hline (27) & $.132^{* * * *}$ & $-.031^{* * * *}$ & .013 & $.347^{* * * *}$ & $-.081^{* * * *}$ & .012 & $.056^{* * * *}$ & $.018^{*}$ & $-.092^{* * * * *}$ & $-.305^{\text {**** }}$ & $-.114^{* * * * *}$ & $.049^{* * * *}$ & $.085^{* * * *}$ & $.062^{\text {****** }}$ \\
\hline (28) & $.150^{* * * *}$ & $-.052^{* * * *}$ & .010 & $.345^{* * * *}$ & $-.065^{* * *}$ & .004 & $.084^{* * * * *}$ & $-.023^{*}$ & $-.090^{* * * * *}$ & $-.288^{* * * *}$ & $-.074^{* * * *}$ & $.027^{* * * *}$ & $.099^{* * * *}$ & $.031^{* *}$ \\
\hline mean & .000 & .000 & .000 & 98.563 & 21.957 & .495 & .084 & .230 & .055 & .163 & .249 & .144 & .007 & .398 \\
\hline$S D$ & 1.000 & 1.000 & 1.000 & 15.547 & 1.774 & .500 & .277 & .421 & .228 & .370 & .432 & .351 & .085 & .490 \\
\hline
\end{tabular}

Note. $\quad(1)=$ alcohol; $(2)=$ tobacco; $(3)=$ drugs; $(4)=$ childhood intelligence; $(5)=$ age; $(6)=$ sex; $(7)=$ Asian; $(8)=$ black; (9) = Native American; $(10)=$ Hispanicity; $(11)=$ Catholic; $(12)=$ Protestant; $(13)=$ Jewish; $(14)=$ other; $(15)=$ marital status; $(16)=$ parenthood; $(17)=$ education; $(18)=$ earnings; (19) = political attitude; (20) = religiosity; (21) = general life satisfaction; $(22)=$ medication for stress; $(23)=$ stress by not medical help; $(24)=$ frequency of socialization with friends; $(25)=$ number of sex partners in 12 months; (26) = childhood family income; (27) = mother's education; $(28)=$ father's education.

${ }^{*} p<.05 .{ }^{* * *} p<.01 .{ }^{* * * *} p<.001$. 


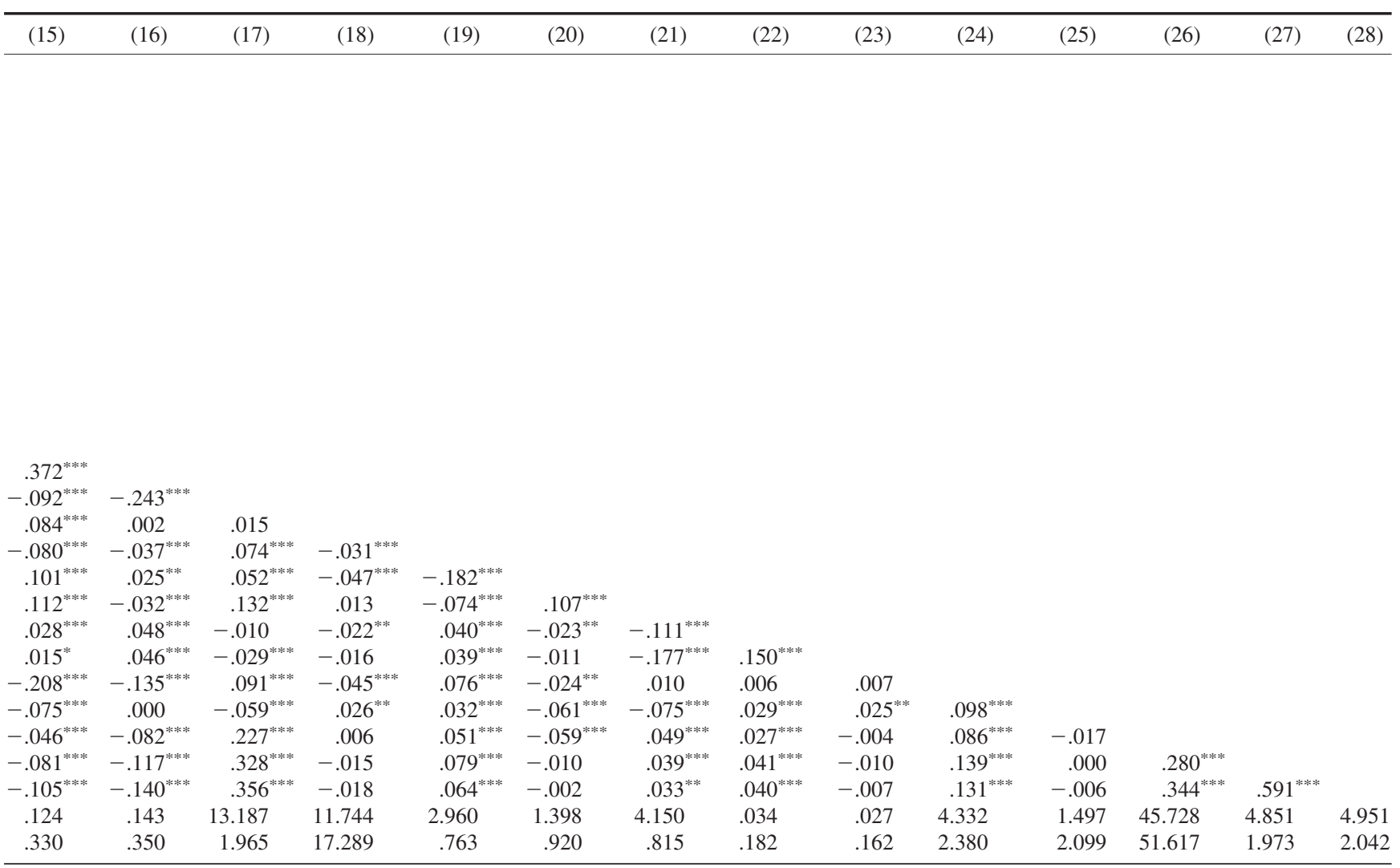

Received July 19, 2010

Revision received September 12, 2010

Accepted September 15, 2010 